Research Article

\title{
Mathematical Modeling of THD Mitigation Using HAPF for UPS System with Experimental Analysis via Hybrid Interface of Optical USB and Power Quality Meter
}

\author{
Mahender Kumar $\mathbb{I D}^{1}{ }^{1}$ M. A. Uqaili, ${ }^{1}$ Z. A. Memon, ${ }^{1}$ and Bhagwan Das ${ }^{2}{ }^{2}$ \\ ${ }^{1}$ Department of Electrical Engineering, Mehran University of Engineering and Technology, Jamshoro, Pakistan \\ ${ }^{2}$ Department of Electronic Engineering, Quaid-e-Awam University of Engineering, Science and Technology, Nawabshah, \\ Sindh, Pakistan \\ Correspondence should be addressed to Mahender Kumar; kumarlovesh025@gmail.com
}

Received 9 June 2021; Revised 17 August 2021; Accepted 1 September 2021; Published 29 September 2021

Academic Editor: Dao B. Wang

Copyright (c) 2021 Mahender Kumar et al. This is an open access article distributed under the Creative Commons Attribution License, which permits unrestricted use, distribution, and reproduction in any medium, provided the original work is properly cited.

\begin{abstract}
This paper discusses a novel analysis scheme based on the hybrid interface of Optical USB and Power Quality Meter for measuring Total Harmonic Distortion (THD) that exists in the Uninterruptable Power Supply (UPS) system and connected load. The designed hybrid interface experimentally analyzes the power quality and harmonics of the Uninterrupted Power Supply (UPS) system, and mitigation is proposed with the proposed Single-Phase Hybrid Active Power Filter (HAPF) based on instantaneous Power Theory (PQ) with hysteresis control technique and synchronous frame reference (DQ) with hysteresis control techniques at nonlinear load. This study authenticates and gives appropriate measurements in analyzing the harmonics and voltage distortion during conversion of power. The designed work offers the compensation and elimination of harmonic currents using PQ and DQ theory at different nonlinear loads. The proposed HAPF for the UPS system has demonstrated the significant reduction in THD using proposed Power Theory (PQ) with hysteresis control technique from $46.58 \%$ to $1.51 \%$ and by using DQ theory with hysteresis control technique has reduced THD from $46.58 \%$ to $1.38 \%$. Finally, the results are compared between PQ and DQ. It is validated via results that DQ theory eliminated harmonics and also having less THD as compared to PQ-theory. Furthermore, one of the key aspects of the work is the analysis of power quality using Optical USB Interface (OC4USB) and FLUKE series power quality analyzer.
\end{abstract}

\section{Introduction}

The roles of electronic instruments in the electrical devices have brought the significant advancement by introducing the new features for the measurement of power, energy, and Total Harmonic Distortion (THD) through power quality analyzer [1-4]. It has been observed that electronics load connected with the power system will offer greater efficiency and sustainability with a leading drawback of harmonic distortion. Moreover, the high number of switching devices over the grid will yield harmonics in the system, and hence, the concern of eliminating them arises. These harmonics are produced from the nonlinear load connected with supply mains $[5,6]$. Harmonics are always serious and produce harmful problem to the power system [7]. In the electrical power system, whenever unbalance occurs in the threephase system, it causes excessive flow of currents in the neutral wire. In addition, harmonics, burden of reactive power, unhinge, and unwarranted neutral currents yield poor power factor and low efficiency that origin the transients. These are also affecting the distribution levels of voltage [8]. Due to the excessive reactive power in the system which results in high utilization of generating stations that produce high losses in transmission line, this will create the need of injecting reactive power at load sides in order to have smooth operation of systems [9]. Nonlinear loads are to be preferred in the power system such as Uninterrupted Power Supply (UPS), Controlled Voltage Controlled Frequency 
(CVCF) system, and Variable voltage Variable Frequency (VVVF) system. Nonlinear loads have not had the response in terms of sinusoidal shape and thus lead to drops in voltages at distribution [10]. There are some drawbacks found for harmonic current due to hotness, congestion, and disruption in control. THD is the sum of all harmonics in a system that describes the deviation degree for nonsinusoidal attributes. In the electrical system at low voltage, the singlephase USP system has a high $\mathrm{THD}_{\mathrm{U}}$ level which is about $2-4 \%$, whereas the $\mathrm{THD}_{\mathrm{I}}$ level is around $80 \%-40 \%$. However, single-phase VFD experimentally measures threephase induction motors' $\mathrm{THD}_{\mathrm{U}}$ value of $2.95 \%$ and the $\mathrm{THD}_{\mathrm{I}}$ as $97.98 \%$ from the fundamental. Moreover, in the three-phase system, due to unbalanced current flow in the neutral wire, it surpluses in the unbiased conductor and could be the major reason of unpredicted nimble of circuit breakers because of which harmonic mitigation techniques are used to make system free from harmonics $[9,11-15]$. There are various Harmonics Mitigation Techniques proposed. The most common is using the filter using any type from Passive filters, APF, SAPF, and HAPF. However, the advanced form of the filter is observed. Hybrid Active Power Filters (HAPFs) are used to improve power conditioning. They generate an unambiguous current inside the components to abandon harmonics because of nonlinear loads [16-18] and Hybrid Filter power in the active mode [19]. The harmonic suppression from the system is the key aspect for utilities and the users nowadays. In the literature, HAPF is considered to be a good solution for harmonic suppression [11] as it can provide relief from harmonics and reactive power at the similar instant; however, power quality is affected because of negative sequence components and swell and sag of voltages [12]. Total harmonic distortion (THD) and reactive power are analyzed by various techniques. The techniques are PQ [9], CPT [16], SAPF [17, 18], A-F-HCC, [20] DQ [21], and many more with introduction of the neural network and fuzzy-based design in the mentioned systems. It is illustrated in [9] that, in the case of asymmetrical conditions, the $\mathrm{PQ}$ technique is not reliable in comparison to CPT and DQ because PQ and CPT control techniques lead in distortion in voltages, whereas DQ technique offers the exact sinusoidal results. When dynamic response of the system is compared, it was concluded that the DQ control method has faster dynamic response than the PQ method [9]. Hence, researchers proved through MATLAB Simulation that the $d$-q method has lower THD then the $p-q$ method. As a result, DQ performs better than PQ technique as stated in [16]. APF minimizes harmonics under the conditions of balanced and unbalanced nonlinear loads [17]. It is discussed in [18] that fuzzy and conventional PI can play vital role in diminishing the harmonic with minimum THD in all operating scenarios and IEEE-519 standard results $5 \%$ attainment in harmonic reduction [18]. A 3-phase SAPF using neutral-point diode clamped inverter using the fuzzy logic current controller provided in [19] to mitigate harmonics, and the results show different nonlinear loads in different scenarios. Furthermore, the novelty of this work is that experimental THD analysis is performed for the UPS system connected with nonlinear load using the hybrid interface of Optical USB Interface (OC4USB) and Power Quality Meter. On the basis of these experimental results, the authors have proposed novel HAPF for the THD mitigation of the UPS system connected with nonlinear using SinglePhase Instantaneous PQ technique and Single-Phase DQ Reference Frame technique with the Hysteresis Controller. THD of the system has been eliminated with PQ technique up to $1.51 \%$ and with DQ technique up to $1.38 \%$.

\section{Design and Development of Hybrid Interface Using Optical USB and Power Quality Meter for Experimental Analysis of THD in UPS System}

The design and development of Hybrid Interface using Optical USB and Power Quality Meter for experimental analysis of Total Harmonic Distortion in the UPS system connected with nonlinear load are performed, as shown in Figure 1, and on basis of experimental results of proposed novel HAPF for reduction in THD. The rapid expansion of UPS systems raises concerns about harmonic distortion from UPS system, inverters, and nonlinear loads. To evaluate the harmonic generation process, this study presents a general model that is a modification of the standard control structure diagram. It summarizes the causes of current harmonics and analyzes their relationship to output power. The theoretical conclusion and analysis are confirmed by both modeling and experimental evaluation $[1,2]$. To analyze the harmonic generation process caused by a singlephase UPS system, a general model was presented, modified from the traditional control block diagram.

In the first step, the hybrid design interface of Optical USB and Power Quality Meter is used for experimental analysis to measure THD. In the second step, mathematical modeling of Single-Phase Instantaneous Power Theory (PQTheory) is described, and after that, the MATLAB-based Simulink model is developed and implemented. Similarly, mathematical modeling of Single-Phase DQ Reference Frame Theory is carried out and after that, the Simulink model is developed. HAPF architecture is given in Figure 2 The single line diagram HAPF for the UPS system is drawn by utilizing a low-evaluated SAPF and an ease shunt aloof L.C filters.

The proposed HAPF has the benefits of both dynamic and latent filters and takes out the drawbacks of unadulterated dynamic and inactive filters. The schematic block diagram of control of HAPF for UPS system is shown in Figure 3.

The proposed HAPF combination involves an inactive passive filter and a shunt APF with voltage source inverter (VSI) connected with a DC capacitor. Figure 3 presents the power and control circuit of the proposed HAPF along with a UPS system connected with nonlinear load with a source voltage. The VSI works in the current-controlled mode (CCM) with the use of a fixed-band hysteresis current controller. In the proposed control system for the HAPF, the source current is needed to be sinusoidal to yield a perfect power factor and harmonics. 


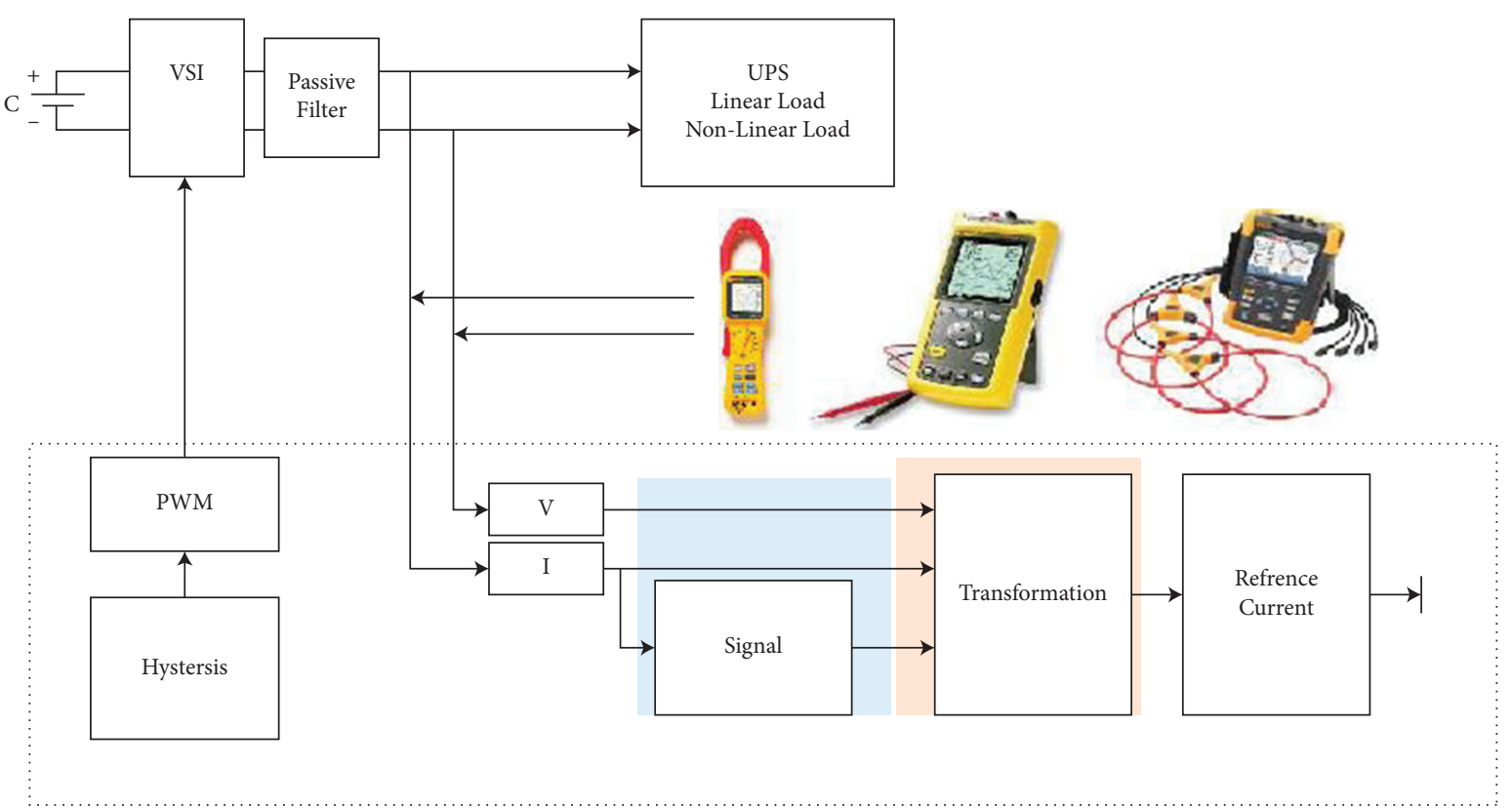

FIgURE 1: Experimental setup for power and THD measurement diagram of the UPS system.

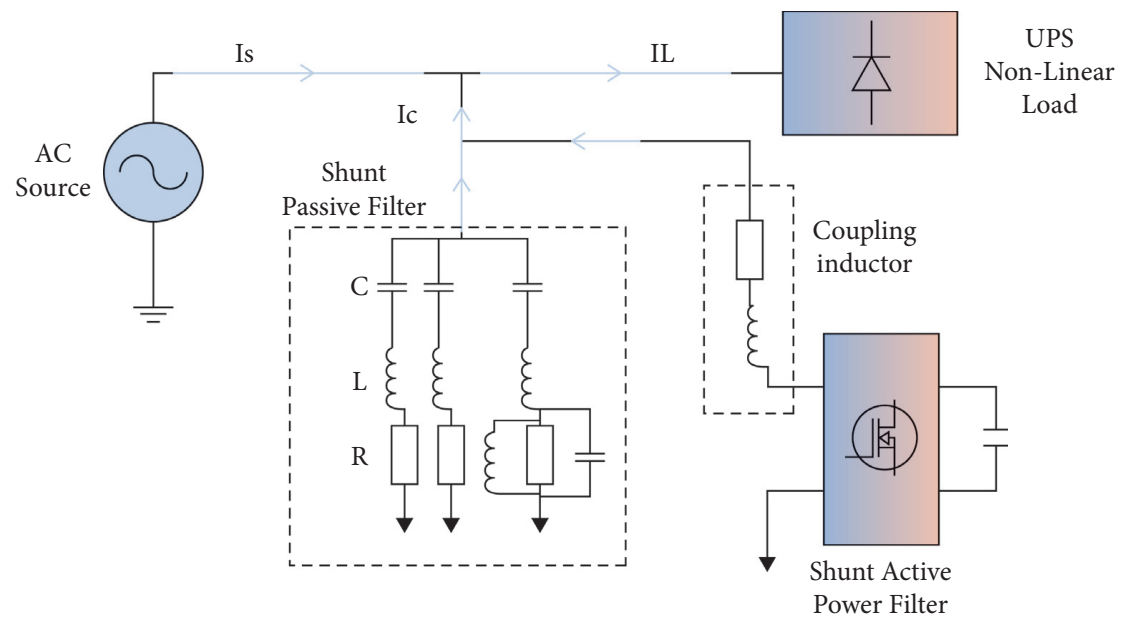

FIGURE 2: Single line diagram HAPF for the UPS system.

2.1. Hybrid Interface Using Optical USB and Power Quality Meter for Analyzing Total Harmonic Distortion (THD) of UPS System. In this work, one of the main aspects of experimental analysis for measuring power quality and Total Harmonic Distortion (THD) in the UPS system connected with nonlinear load is performed with the proposed experimental setup, as shown in Figures 4(a)-4(d), that discussed about hybrid interface using optical USB and power quality meter for analyzing total harmonic distortion for UPS. Energy Analyzer FLUKE 435 SERIES II with additional equipment of FLUKE 43 B/003 Power Quality Analyzer is used to measure THD analysis; in addition, Optical USB Interface Cable (OC4USB), as shown in Figure 4(c), is used to interface the cable. The connections are developed such as the optically-isolated serial port is linked with Power Quality Analyzer using the standard BUS with the PC. The device of the harmonic analysis system consists of DSP and FPGA and consists of LCD, A-D, and F.F.T and network communication unit. It can perform not only detection and measurement functions such as A-D sampling and F.F.T processing but also harmonic power flow analysis functions. It can also provide network communication and display functions. A new type of automation software tool with more accurate response is expected to be used to detect three major power quality disturbances: transient, voltage drop, and total harmonic distortion measurement and detection. A new research concept on energy quality is proposed. The concept integrates power system modeling, classification and characterization of power quality events, sensitivity of equipment to event failures, and identification of where they occur in an integrated framework.

This Optical USB Interface Cable (OC4USB) supports the Power Quality analyzers of FLUKE 43, 43 B, 430 and 


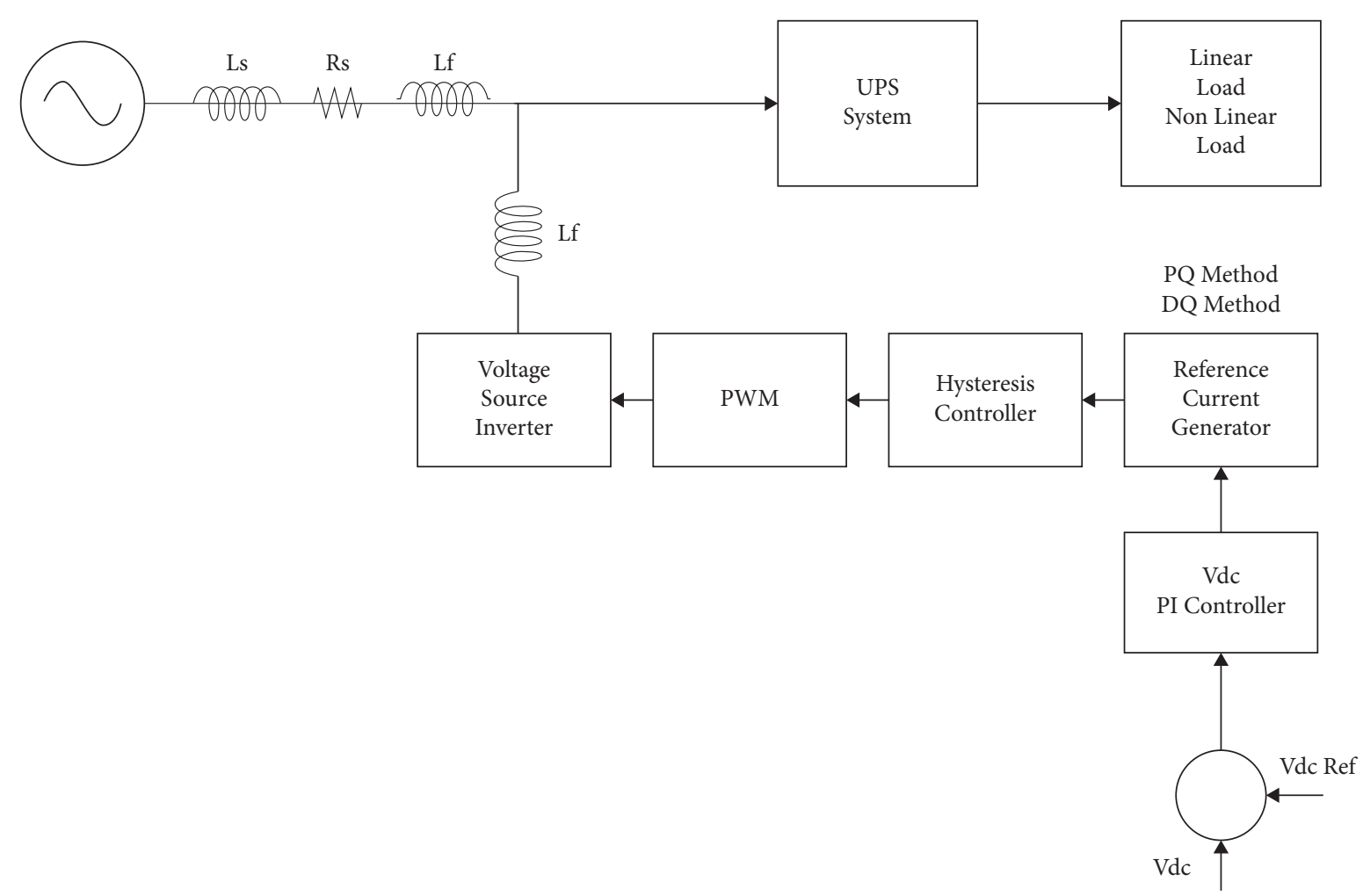

FIGURE 3: Block diagram of control of HAPF for the UPS system.



(a)

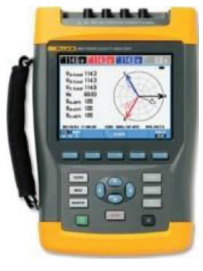

(b)

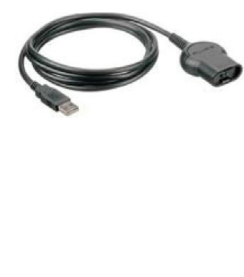

(c)

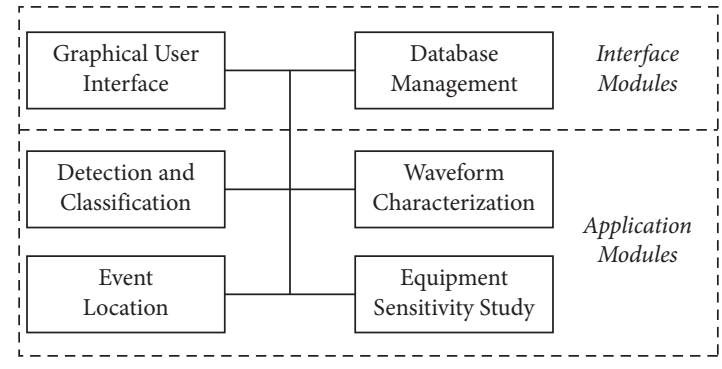

(d)

FIgure 4: (a-d) Power Quality and Energy Analyzer FLUKE 435 and 43b and Optical USB Interface Cable (OC4USB) with Experimental Setup for THD Analysis of the UPS system.

120 and 190 Scope Meters as well Optical USB Interface Cable (OC4USB). In the next section, experimental results are given for Total Harmonic Distortion (THD) and it is energy analysis is provided using Hybrid Interface using Optical USB and Power Quality Meter. A new practical method was proposed and implemented to integrate the processing and analysis of energy quality data and modeling of systems and equipment into a single integrated framework. Several methods have been proposed to detect, classify, characterize, and evaluate the susceptibility of equipment to power quality events [1-4]. The proposed solution has been confirmed by experimental and simulation results. On the basis of these experimental result for mitigation of harmonic from UPS system, proposed Hybrid Active power Filter using PQ and DQ theory and results are also compared.
2.2. Real Time Experimental THD Analysis of Single-Phase UPS System through Hybrid Interface Using Optical USB and Power Quality Meter. In this research, Single-Phase UPS system has been connected with different nonlinear load for experimental THD Analysis through Optical USB Interface Cable (OC4USB) with FLUKE 435 SERIES II and FLUKE $43 \mathrm{~B} / 003$ Power Quality Analyzer as experimental setup is shown in Figure 4. HAPF is developed on the basis of experimental result of THD, as shown in Figure 5, to mitigate harmonics; otherwise, it creates many problems in power quality. Poor power quality with high THD attains the hotness in transformers and loss in the equipment $[9,16]$.

UPS system is used in all sectors such as residential, commercial, industrial, hospitals, and communication for reliable, uninterrupted, and instant backup power. In some countries, use of the UPS system is very common due to load 




(a)
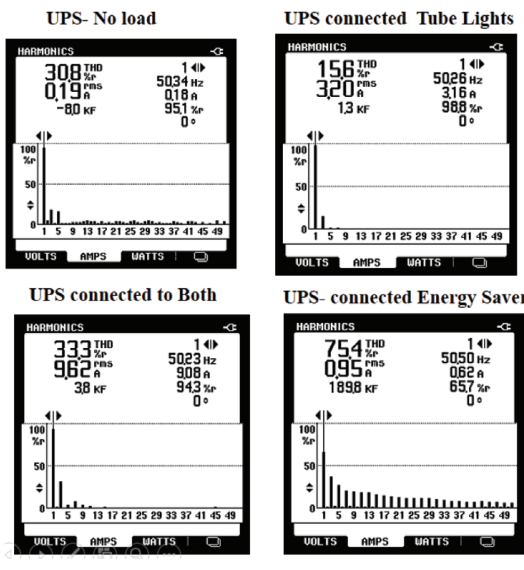

(b)

FIgURE 5: (a-b) Single-Phase UPS system experimental THD analysis results.

shedding as power generation is not sufficient. Locally manufactured UPS without filter has greater losses in terms of THD and poor efficiency, as presented in Table 1.

Table 1 shows measurement for UPS efficiency and THD at different types of loads during charging and discharging of batteries. It is also observed from the experimental results that average THD of the UPS system is more than $46 \%$, and on basis of this proposed latest HAPF, it is more effective and efficient technique for mitigation of THD as compared to other passive filters and active power filters (APF).

\section{Design and Modeling of HAPF Based on Single-Phase Instantaneous PQ Technique}

Instantaneous PQ technique is mostly to be used for the three-phase system by using the transformation technique named as Clarke. In this voltage and current transformation from abc to $\alpha \beta 0$, orthogonal is to be performed, and the phase voltage is in the form of orthogonally. However, recently the PQ technique is also used for the single-phase system [16, 17]. In this work, on basis of the experimental result of THD analysis of the UPS system, HAPF Matlab model is developed, and reference current is obtained by using PQ-Theory and hysteresis controller. The Design and Modeling of SinglePhase system Instantaneous PQ technique are explained in two phases. In the first phase, modeling of the proposed system is explained, and after that, its simulation design is given.

3.1. Mathematical Modeling of Single-Phase Instantaneous Power Technique. The modeling of Single-Phase Instantaneous Power Technique is initiated by introducing the Clarke transformation first for active and reactive component calculation, and after that, inverse Clarke transformation for references' parameters is modeled. The mathematical modeling is illustrated in Figure 6.
Clarke transformation for the active and reactive component calculation is elaborated in equation (1) for SinglePhase Instantaneous Power Theory (PQ-Theory) [22]:

$$
\left[\begin{array}{c}
v_{S \alpha}(\omega t) \\
v_{S \beta}(\omega t)
\end{array}\right]=\left[\begin{array}{c}
v_{S}\left(\omega t+\varphi_{V}\right) \\
v_{S}\left(\omega t+\varphi_{V}+\frac{\pi}{2}\right)
\end{array}\right]=\left[\begin{array}{c}
V_{m} \sin \left(\omega t+\varphi_{V}\right) \\
v_{m} \cos \left(\omega t+\varphi_{V}\right)
\end{array}\right] .
$$

The Clarke transformation-based load current is represented in $\alpha \beta$ coordinates for the active and reactive component calculation, as shown in the following equation [23]:

$$
\left[\begin{array}{c}
i_{L \alpha}(\omega t) \\
i_{L \beta}(\omega t)
\end{array}\right]=\left[\begin{array}{c}
i_{L}\left(\omega t+\varphi_{I}\right) \\
i_{L}\left(\omega t+\varphi_{I}+\frac{\pi}{2}\right)
\end{array}\right] .
$$

Hence, $V_{m}, \omega, \phi_{V}$, and $\phi_{I}$ are the voltage and frequency of source, source-voltage phase, and load current. Singlephase prompt reactive and active powers in the form of $\alpha \beta$ are discussed in the following equation [24]:

$$
\left[\begin{array}{c}
p \\
q
\end{array}\right]=\left[\begin{array}{cc}
v_{S \alpha} & -v_{S \beta} \\
v_{S \beta} & v_{S \alpha}
\end{array}\right]\left[\begin{array}{c}
i_{L \alpha} \\
i_{L \beta}
\end{array}\right] .
$$

Single-phase prompt active and reactive using PQ technique from Clarke transformation of equation (1) is given in following equations [25]:

$$
\begin{aligned}
& p=\bar{p}+\tilde{p}, \\
& q=\bar{q}+\widetilde{q} .
\end{aligned}
$$

In this work, $\bar{p}$ and $\bar{q}$ are DC part of the signal and $\tilde{p}$ and $\widetilde{q}$ are AC part of the signal that express active and reactive power [26]. Therefore, active component power of SinglePhase Instantaneous Power Theory (PQ-Theory) using Clarke transformation is calculated from equation (3): 
TABLE 1: UPS efficiency and THD.

Efficiency of UPS and THD in Pakistan

\begin{tabular}{lcccc} 
Charging efficiency & Discharging efficiency & Overall efficiency & Average THD without filter & Average THD with filter \\
\hline$<79.54 \%$ & $<64 \%$ & $<60 \%$ & $>46 \%$ & $<2 \%$
\end{tabular}

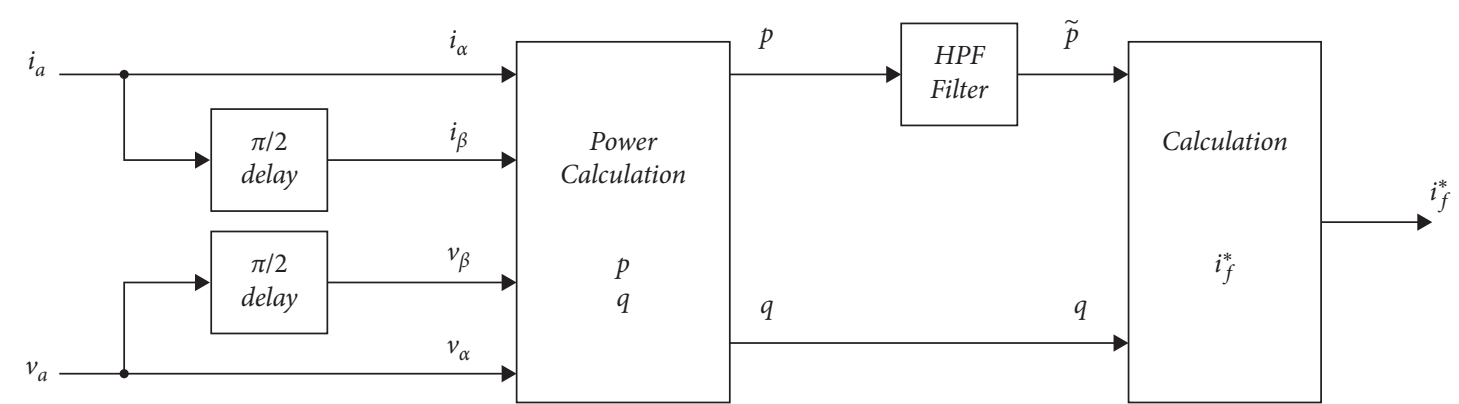

FIgure 6: Mathematical modeling of the Single-Phase Instantaneous Power Technique.

$$
\begin{aligned}
{\left[\begin{array}{l}
i_{L \alpha, p} \\
i_{L \beta, p}
\end{array}\right] } & =\left[\begin{array}{cc}
v_{S \alpha, 1} & -v_{S \beta, 1} \\
v_{S \beta, 1} & v_{S \alpha, 1}
\end{array}\right]^{-1}\left[\begin{array}{l}
\bar{p} \\
0
\end{array}\right] \\
& =\frac{1}{v_{S \alpha, 1}^{2}+v_{S \beta, 1}^{2}}\left[\begin{array}{cc}
v_{S \alpha, 1} & -v_{S \beta, 1} \\
v_{S \beta, 1} & v_{S \alpha, 1}
\end{array}\right]^{-1}\left[\begin{array}{l}
\bar{p} \\
0
\end{array}\right] .
\end{aligned}
$$

Hence, distorted load current is compensated by the injection current of the hybrid active power filter to achieve the sinusoidal source current of the system [27], and then, the reference current in terms of the source value is from equation (6) that is illustrated in the following equation [24]:

$$
i_{S, \text { ref }}=i_{L \alpha, P=} \frac{v_{S \alpha, 1}}{v_{S \alpha, 1}^{2}+v_{S \beta, 1}^{2}} \times \bar{p} .
$$

In this condition, DC calculations of voltages are constants, and an active power $P_{\mathrm{dc}}$ of Single-Phase Instantaneous Power Technique using Clarke transformation and the compensation of APF power losses need to be calculated, as shown in following equations [28]:

$$
\begin{aligned}
& i_{S, \text { ref }}=i_{L \alpha, P=} \frac{v_{S \alpha, 1}}{v_{S \alpha, 1}^{2}+v_{S \beta, 1}^{2}} \times\left(\bar{p}+p_{\mathrm{dc}}\right) \\
& i_{S, \text { ref }}=i_{L \alpha, P}=\frac{v_{S \alpha, 1}}{v_{S \alpha, 1}^{2}+v_{S \beta, 1}^{2}} \times\left(\bar{p}+p_{\mathrm{dc}}\right)-p_{\text {dc.equal }} .
\end{aligned}
$$

For final reference, current of an active power $P_{\mathrm{dc}}$ of Single-Phase Instantaneous PQ technique is calculated using the following equation [16]:

$$
i_{S, \text { ref }}=\frac{\left(v_{S \alpha, 1} i_{L \alpha, 1}+v_{S \beta, 1} i_{L \beta, 1+p_{\mathrm{dc}}}\right) v_{S \alpha, 1}}{v_{S \alpha, 1}^{2}+v_{S \beta, 1}^{2}}-p_{\mathrm{dc.equal}} \text {. }
$$

It is discussed in equations (7)-(10) that source voltage is significantly contributing in the orientation current for single-phase HAPF. During system operations, occurrence in voltages with distortion in equation (10) straightly impacts the alterations in the system current [17]. Here, the main functionality of HAPF is to produce suitable harmonic currents spikes to balance the compensations because of the selection of suitable hysteresis current control technique.

3.2. Simulation Model of HAPF Based on Single-Phase Instantaneous PQ Technique. The simulation model of Instantaneous PQ technique is demonstrated in Figure 7. The proposed model of Single-Phase PQ technique suggests that the current values at the load side and the voltage value at the source side have $\alpha$-axis and their phases are rightly shifted by $90^{\circ}$ and the fictional $\beta$-axis. Here, for this work, the presumption of purely sinusoidal voltages is observed.

It is represented in the $\alpha \beta$ coordinates, which are fixed for Single-Phase Instantaneous Power Theory (PQ-Theory). The Simulink model is developed using MATLAB for SinglePhase HAFP with the UPS system connected to nonlinear load and for reference current PQ Hysteresis controller technique proposed, as demonstrated in Figure 7. It is shown that nonlinear load is connected with the single-phase source, and the mitigation of THD is implemented by using shunt HAPF with the system.

3.3. Simulation Results of HAPF Based on Single-Phase Instantaneous Power (PQ-Theory). The results attained for mitigation of THD from Single-Phase Instantaneous Power Theory (PQ-Theory) are observed in Figures 8-16, by finding out the THD at nonlinear load without filter and with filters. The results of the designed system is based on parameters such as L-N RMS voltage of $220 \mathrm{~V}$, frequency of $50 \mathrm{~Hz}$, coupling inductance of $0.0035 \mathrm{H}$, coupling resistance of $1 \Omega$, source inductance of $1 e-4 \mathrm{H}$, source resistance of $1 \Omega$, source voltage of $V s=200$ to $-200 \mathrm{~V}$, load current of $I_{L}=4$ to $-4 \mathrm{~A}$, injected/compensated current of $I_{c}=4$ to $-4 \mathrm{~A}$, source current of $I_{s}=5$ to $-5 \mathrm{~A}$, and DC bus voltage capacitor $V_{\mathrm{dc}}=800 \mathrm{~V}$. 


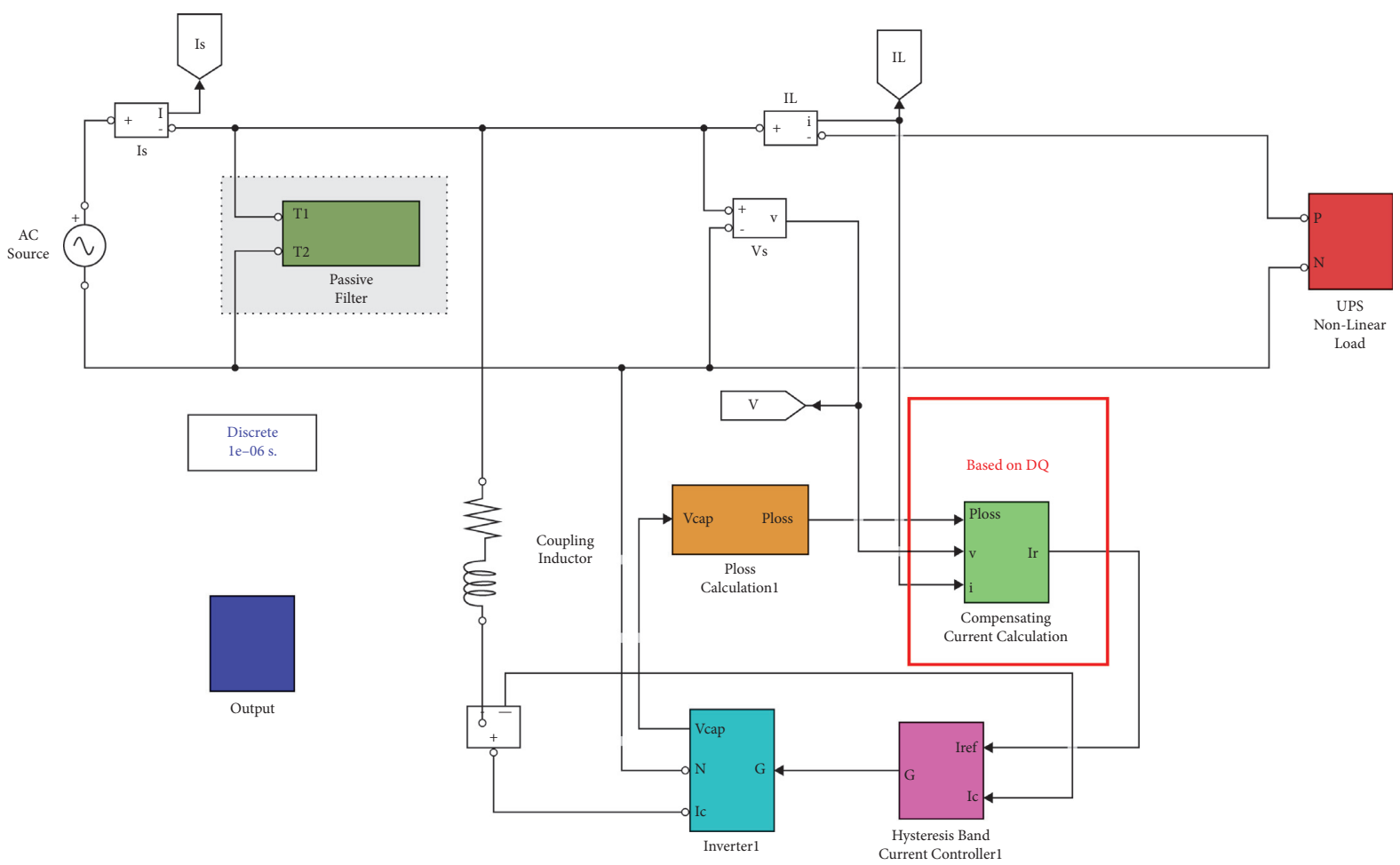

FIgure 7: Simulation model of Single-Phase HAPF for the UPS-PQ hysteresis controller.

Figure 8 describes the source voltage of $V s=200$ to $-200 \mathrm{~V}$ that the measured value of THD that has been observed is $0.00 \%$ with FFT, Figure 9 describes system drawn distorted load current of $I_{L}=4$ to $-4 \mathrm{~A}$, Figure 10 describes HAPF injected/compensated current of $I_{c}=4$ to $-4 \mathrm{~A}$ for the compensation, Figure 11 describes source current of $I_{s}=5$ to $-5 \mathrm{~A}$ for the analysis of THD after HAPF, Figure 12 describes $V_{\mathrm{dc}}$ (voltage capacitor) $800 \mathrm{~V}$ maintained with the PI controller, and Figures 13 and 14 show load current FFT analysis without HAPF. The measured value of THD is equivalent to $46.58 \%$ without the filter. Figures 15 and 16 shows FFT analysis of the system with applied HAPF based on PQ-theory as load current $I_{L}$ THD is achieved $1.51 \%$ after compensation.

\section{Design and Modeling of HAPF Based on Single SRF-DQ Theory}

In this work, the DQ technique for the 1- $\Phi$ HAPF model is designed by making the modifications in the values of current, and the mathematical modeling and simulation design are explained.

4.1. Mathematical Modeling of Single-Phase SRF-DQ Technique. The modeling of Single-Phase DQ Technique for HAPF is demonstrated by adaptation in the current parameters of the single-phase system, as shown in Figure 17. An imaginary variable to attain the orthogonal $\alpha$ and $\beta$ relationship is achieved by phase shifting of $90^{\circ}$. At the instant, the original signal and imaginary signal are combined as corresponding illustration of a single-phase orthogonal $\alpha-\beta$ frame. The mathematical model of SinglePhase DQ Reference Frame Technique is represented in Figure 17.

Figure 17 shows the mathematical model of the singlephase transformation method using reference representation of the designed work, and it is easy to find out the reference source for control technique, by using DQ technique, and load current can be shown as below in the following equation [29]:

$$
\left[\begin{array}{c}
i_{L \alpha} \\
i_{L \beta}
\end{array}\right]=\left[\begin{array}{c}
i_{L}(\omega t+\varphi) \\
i_{L}\left(\omega t+\varphi+\frac{\pi}{2}\right)
\end{array}\right] .
$$

The use of imaginary variable for DQ technique is additional expanded in presenting the DQ technique via $. \alpha-\beta$ frame replacing that yields the DQ technique development as in following equations [30]:

$$
\begin{aligned}
& {\left[\begin{array}{l}
i_{L d} \\
i_{L q}
\end{array}\right]=\left[\begin{array}{cc}
\sin \omega t & -\cos \omega t \\
\cos \omega t & \sin \omega t
\end{array}\right]\left[\begin{array}{l}
i_{L \alpha} \\
i_{L \beta}
\end{array}\right],} \\
& {\left[\begin{array}{l}
i_{L d} \\
i_{L q}
\end{array}\right]=\left[\begin{array}{c}
i_{L d}+i_{L d} \\
i_{L q}+i_{L q}
\end{array}\right]=\left[\begin{array}{l}
i_{L \alpha} \sin \omega t-i_{L \beta} \cos \omega t \\
i_{L \alpha} \cos \omega t+i_{L \beta} \sin \omega t
\end{array}\right] .}
\end{aligned}
$$

In equation (7), $\bar{i}_{L d}$ and $\bar{i}_{L q}$ are DC parts which are basic in terms of current in load $\bar{i}_{L}$ that divided in reactive and active values. And, $\widetilde{i}_{L d}$ and $\widetilde{i}_{L q}$ are AC terms that define the harmonics in terms of active and reactive current. In this work, authors are concerned with the indirect current control scheme. The reference signal for 


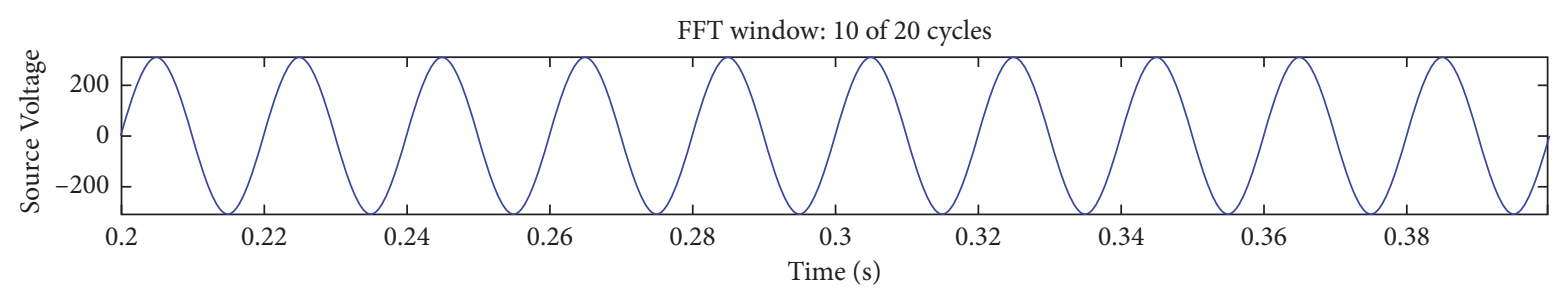

FIgURe 8: Voltage source Vs for HAPF based on Single-Phase Instantaneous Power (PQ-Theory).

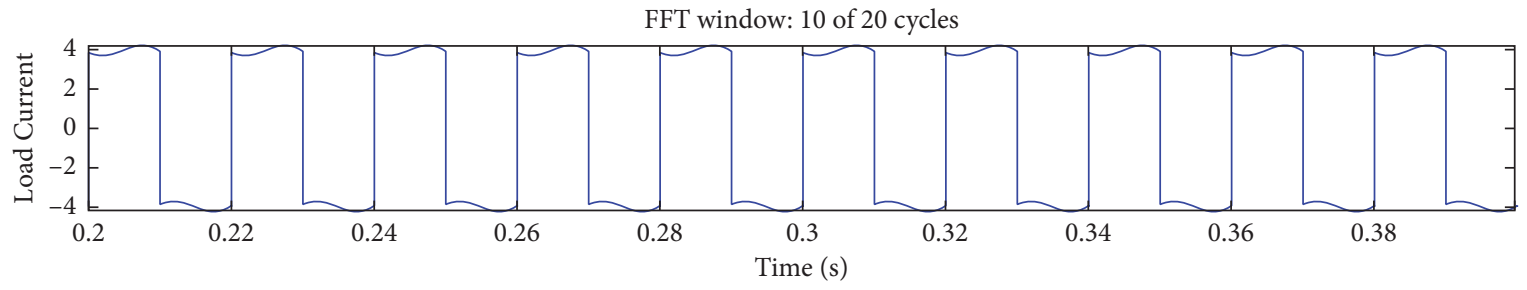

Figure 9: Load current $I_{L}$ for HAPF based on Single-Phase Instantaneous Power (PQ-Theory).

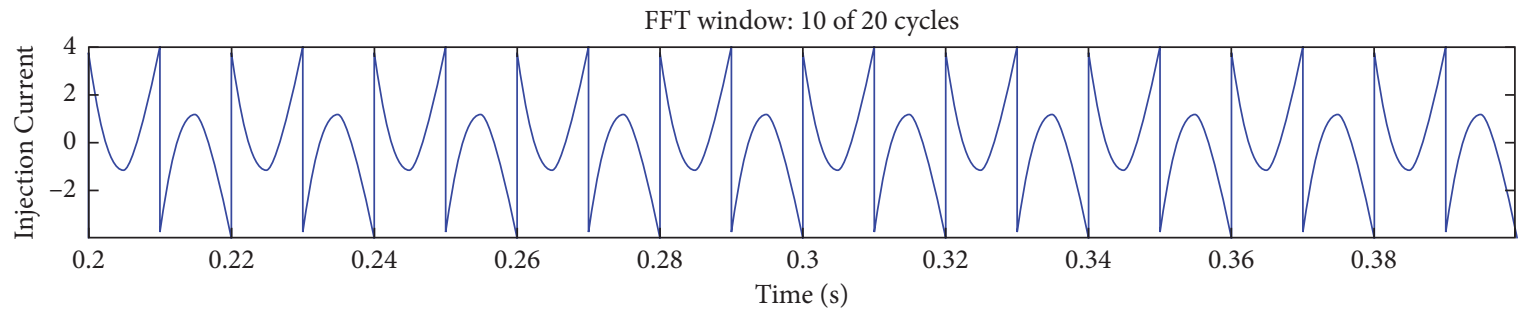

FIgure 10: $I_{c}$ (injected current) for HAPF based on Single-Phase Instantaneous Power (PQ-Theory).

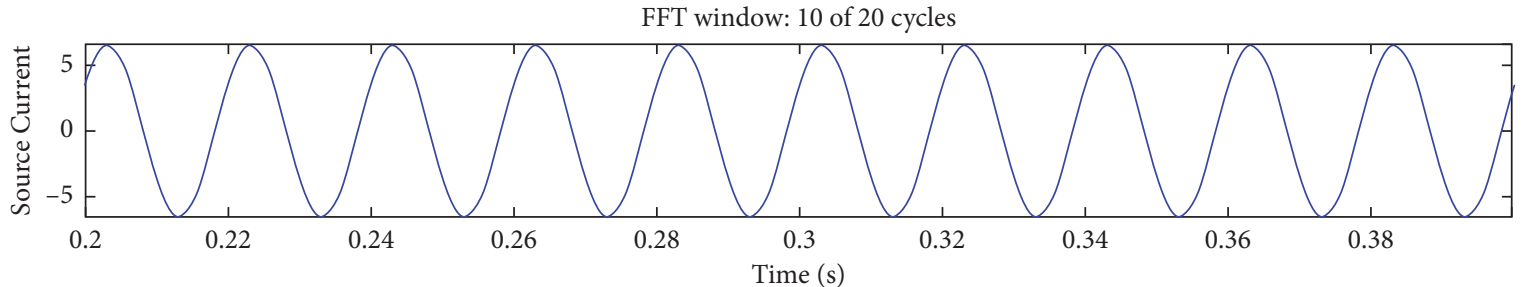

FIgURE 11: $I_{s}$ (source current) is for HAPF based on Single-Phase Instantaneous Power (PQ-Theory).



Figure 12: $V_{\mathrm{dc}}$ (voltage capacitor) for HAPF based on Single-Phase Instantaneous Power (PQ-Theory).

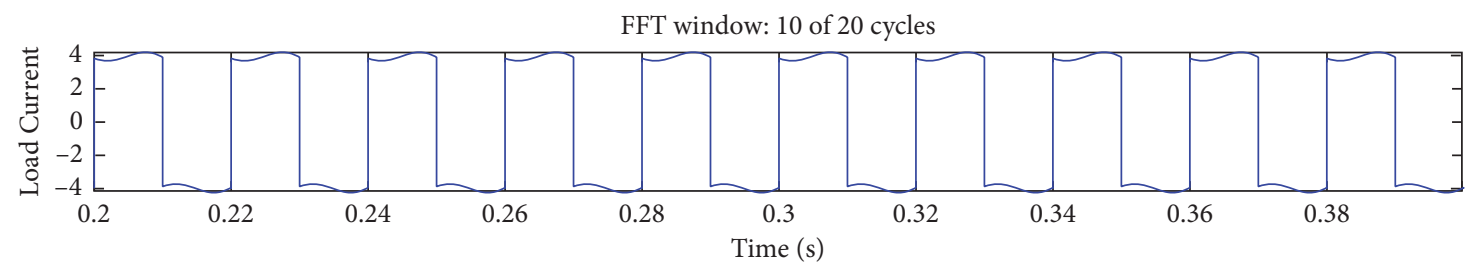

Figure 13: Load current FFT analysis without HAPF based on PQ-Theory. 


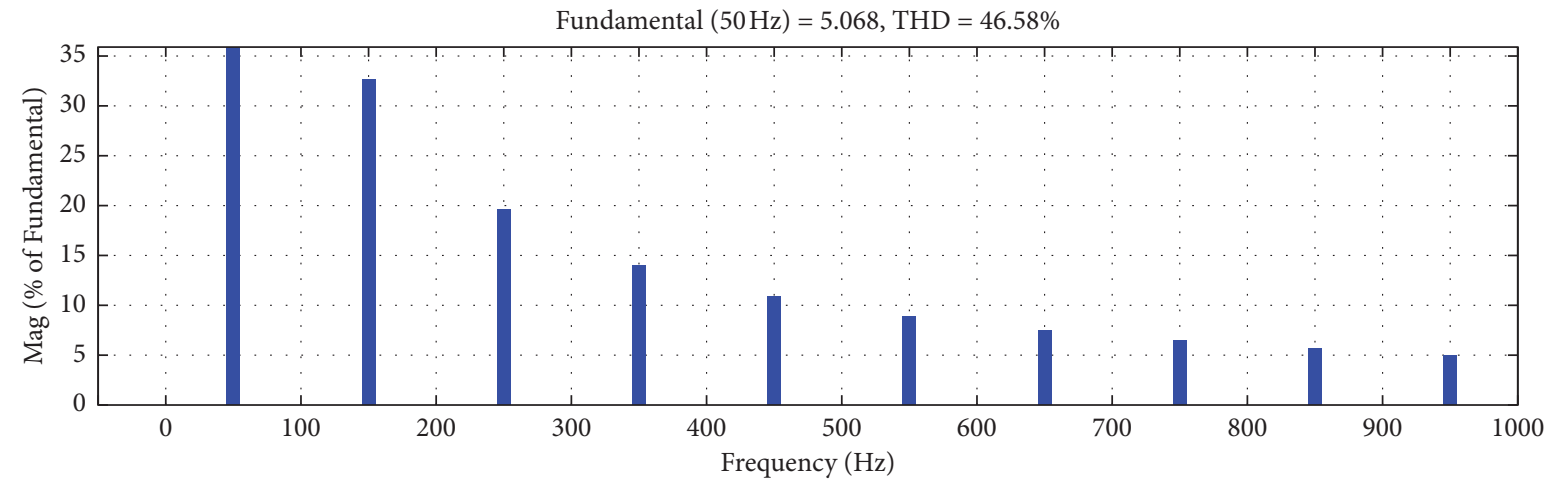

FIgURE 14: Load current $I_{L}$ THD without HAPF-measured THD of $46.58 \%$ before applying the filter.

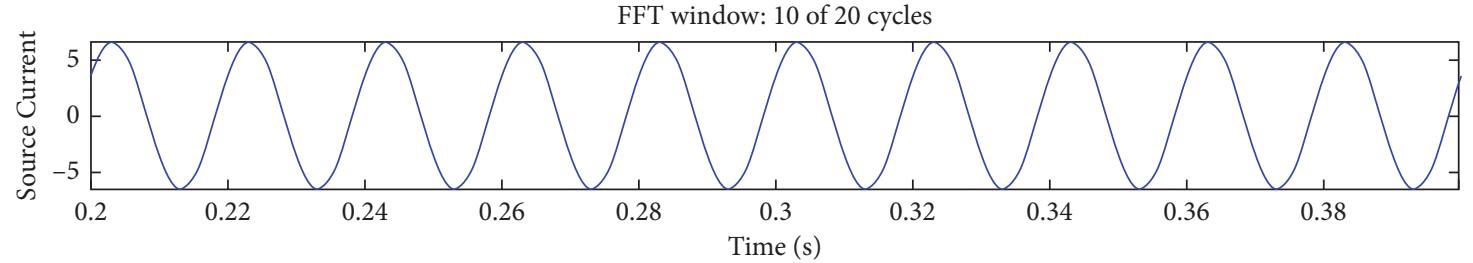

FIgURe 15: Load current $I_{L}$ FFT with HAPF based on PQ-Theory.



Figure 16: Load current $I_{L}$ THD with HAPF measured THD of $1.51 \%$ after applying the filter.

current values is defined in the source as an aspect which is produced with DC part $\bar{i}_{L d}$, as shown in the following equation [31]:

Therefore,

$$
\left[\begin{array}{c}
i_{L d}^{*} \\
i_{L q}^{*}
\end{array}\right]=\left[\begin{array}{cc}
i_{L d} & 0 \\
+0 & +0
\end{array}\right]
$$

The reference signal in terms of current through the $\alpha-\beta$ frame is used to substitute quantities in equations (12) and (14), and its inverse is shown in following equations [32]:

$$
\begin{aligned}
& {\left[\begin{array}{c}
i_{s \alpha}^{*} \\
i_{s \beta}^{*}
\end{array}\right]=\left[\begin{array}{cc}
\sin \omega t & \cos \omega t \\
-\cos \omega t & \sin \omega t
\end{array}\right]^{-1}\left[\begin{array}{c}
i_{L d}^{*} \\
i_{L q}^{*}
\end{array}\right],} \\
& {\left[\begin{array}{c}
i_{s \alpha}^{*} \\
i_{s \beta}^{*}
\end{array}\right]=\left[\begin{array}{cc}
\sin \omega t & \cos \omega t \\
-\cos \omega t & \sin \omega t
\end{array}\right]\left[\begin{array}{c}
\bar{i}_{L d}+i_{\mathrm{DC}} \\
0
\end{array}\right] .}
\end{aligned}
$$

It is necessary to maintain the capacitor current $i_{\mathrm{DC}}$ as a constant DC voltage transversely through the values of the active filter with the PI controller. The term $i_{s \beta}^{*}$ is a fictional component of the main system and can be abandoned as presented in the following equation [33]: 


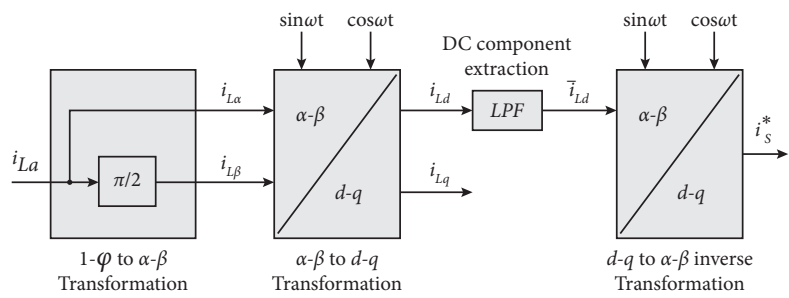

FIgURE 17: DQ Technique mathematical modeling.



FIGURE 18: Model of single-phase synchronous DQ reference technique.

$$
i_{s}^{*}(\omega t)=i_{s \alpha}^{*}(\omega t)=\sin \omega t\left(i_{L d}+i_{\mathrm{DC}}\right) .
$$

As shown in equation (17), the Single-Phase DQ theory is used for reference current for $\operatorname{HAPF}[29,30]$.

4.2. Simulation Model of HAPF Based on Single-Phase DQ Reference Technique. The simulation model of Single-Phase HAPF based on DQ Technique is developed on park transformation but with variation in parameters in order to utilize it for the single phase, as presented in Figure 18.

UPS system is connected with nonlinear load and single-phase source, and HAPF is applied to mitigate THD. The DQ technique-based HAPF system is designed in Matlab Simulink, as presented in Figure 18. HAPF works on DQ technique based on the $\alpha-\beta$ frame. Imaginary variables are orthogonal phase and shifting it by $90^{\circ}$. This single-phase model voltage and current signals are combined by defining the values orthogonally in $\alpha-\beta$ frame. It is based on the single phase for UPS and reference current obtained by using DQ hysteresis controller technique.
4.3. Simulation Results of HAPF Based on Single-Phase DQ Hysteresis Technique. To mitigate the effect of nonlinear load, we used proposed HAPF for the UPS system on the basis of DQ Hysteresis control technique. The results attained for mitigation of THD from DQ Hysteresis control technique are observed in Figures 19-26. DQ Hysteresis control-based HAPF for UPS is based on similar design parameters such as L-N RMS voltage of $220 \mathrm{~V}$, frequency of $50 \mathrm{~Hz}$, coupling inductance of $0.0035 \mathrm{H}$, coupling resistance of $1 \Omega$, source inductance of $1 e-4 \mathrm{H}$, and source resistance of $1 \Omega$.

Figure 19 shows waveform of source voltage of $V s=200$ to $-200 \mathrm{~V}$, Figure 20 depicts load current of system $I_{L}=4$ to $-4 \mathrm{~A}$, whereas Figure 21 shows HAPF injected/compensated current of $I_{c}=4$ to $-4 \mathrm{~A}$, Figure 22 shows system source current of $I_{s}=5$ to $-5 \mathrm{~A}$, and Figure 23 describes DC Bus Voltage Capacitor $V_{\mathrm{dc}}=800 \mathrm{~V}$ maintained with the PI controller. Figures 24 and 25 show load current FFT analysis without HAPF. The measured value of THD is equivalent to $46.58 \%$ without the filter. Figures 26 and 27 show FFT analysis of system with HAPF based on DQ-Theory load current $I_{L}$ THD of $1.38 \%$ has been achieved after compensation. 


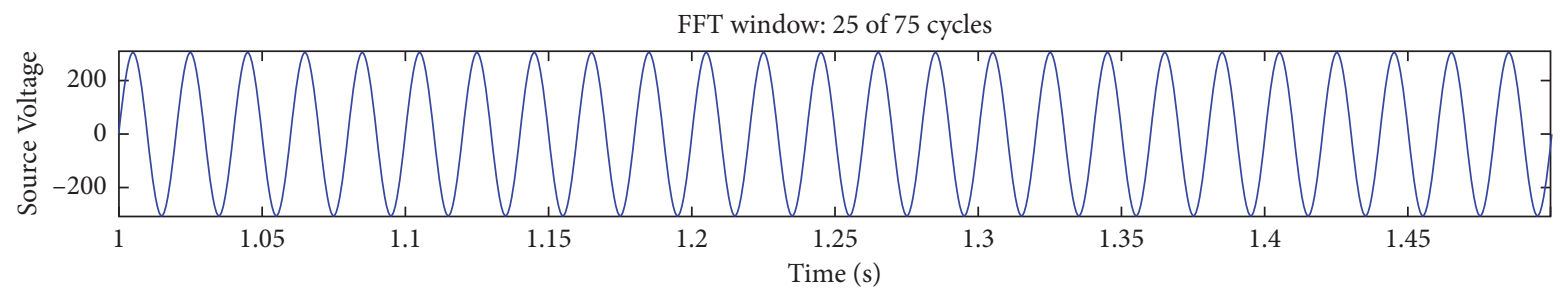

Figure 19: Voltage source Vs for HAPF based on DQ-Theory.

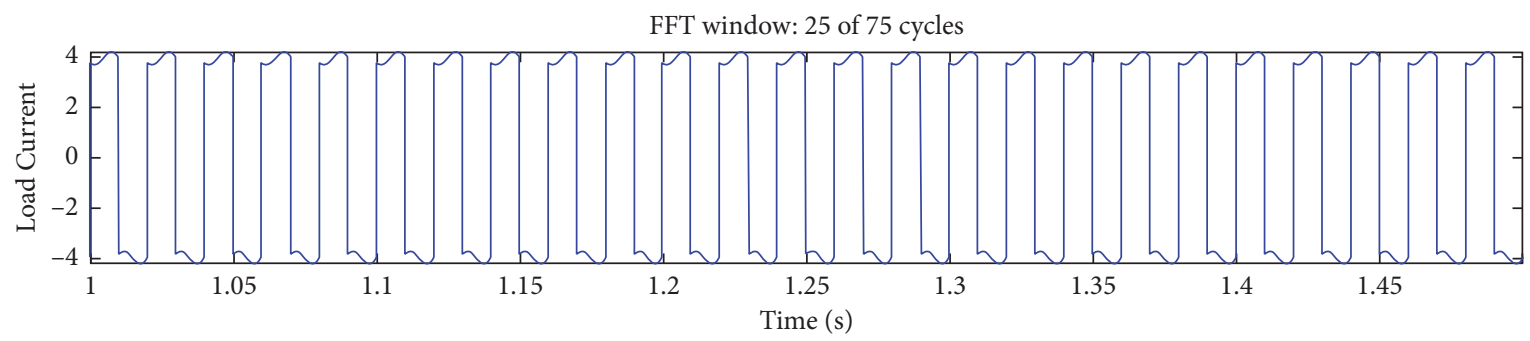

FIgURE 20: Load current $I_{L}$ for HAPF based on DQ-Theory.

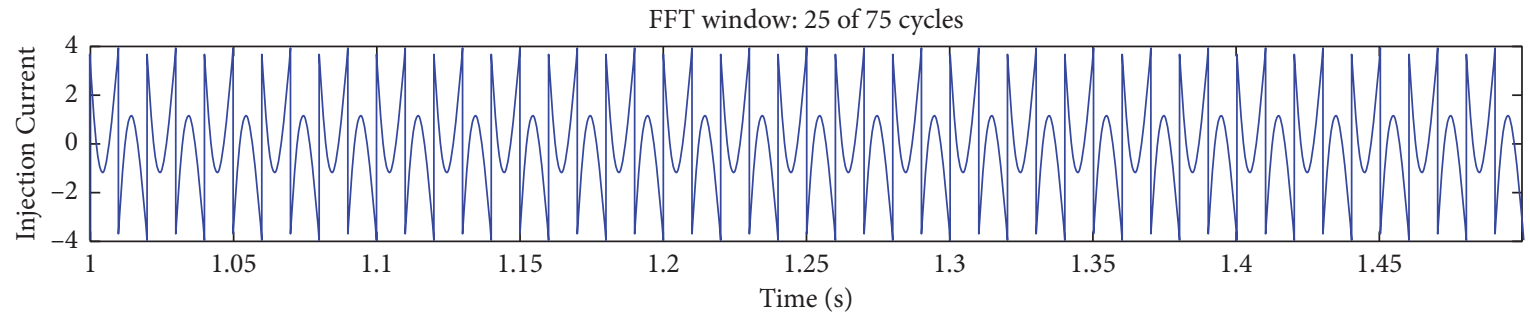

FIGURE 21: $I_{c}$ (injected current) $I_{c}$ for HAPF based on DQ-Theory.



Figure 22: $I_{s}$ (source current) for HAPF based on DQ-Theory.

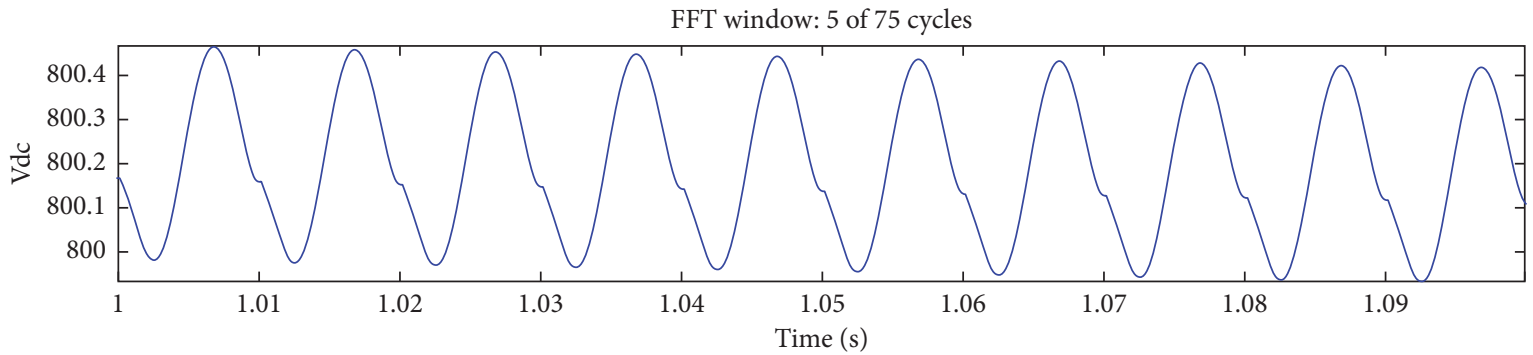

FIgURE 23: $V_{\mathrm{dc}}$ (voltage capacitor) for HAPF based on DQ-Theory. 


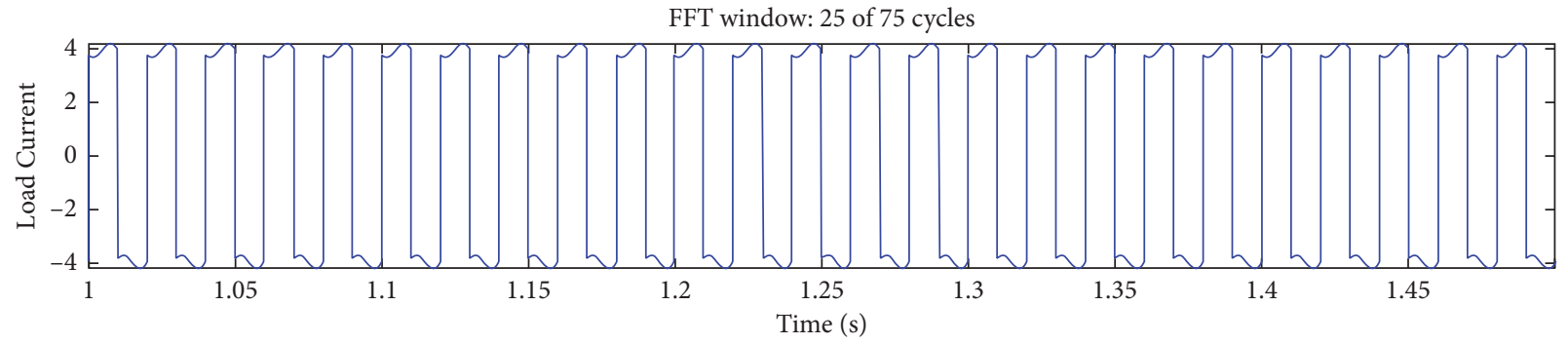

FIGURE 24: Load current FFT without HAPF based on DQ-Theory.

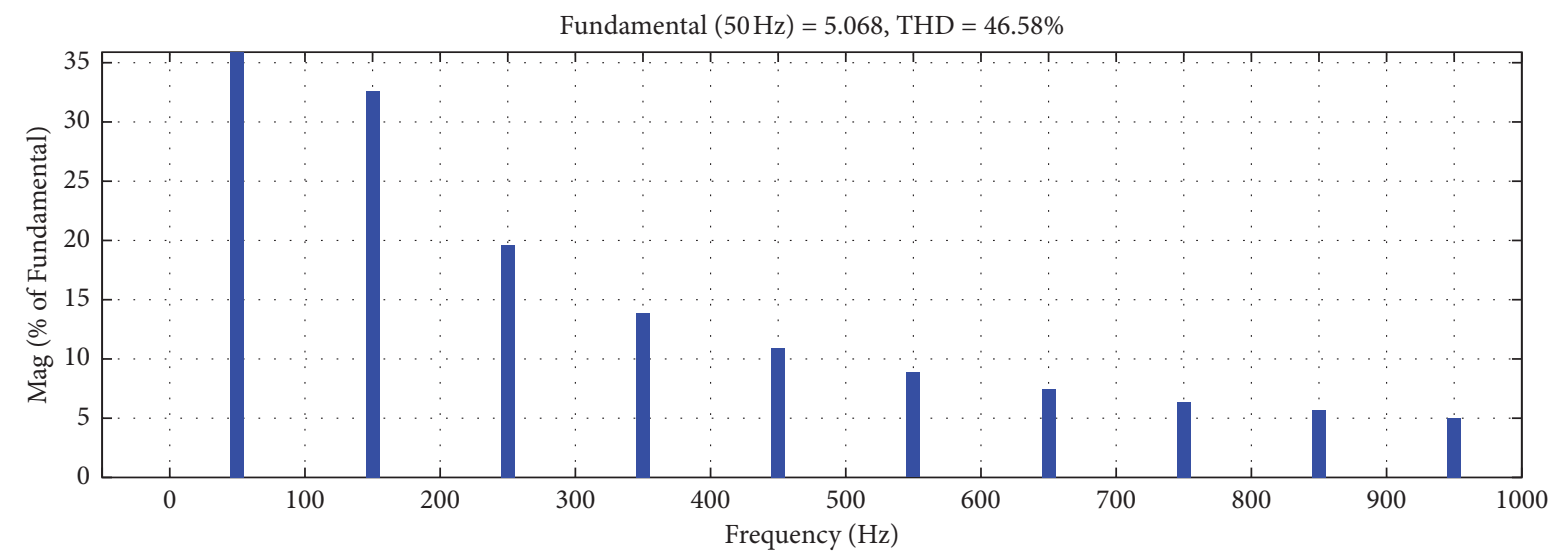

FIGURE 25: Load current IL THD without HAPF measured THD of $46.58 \%$ before applying the filter.

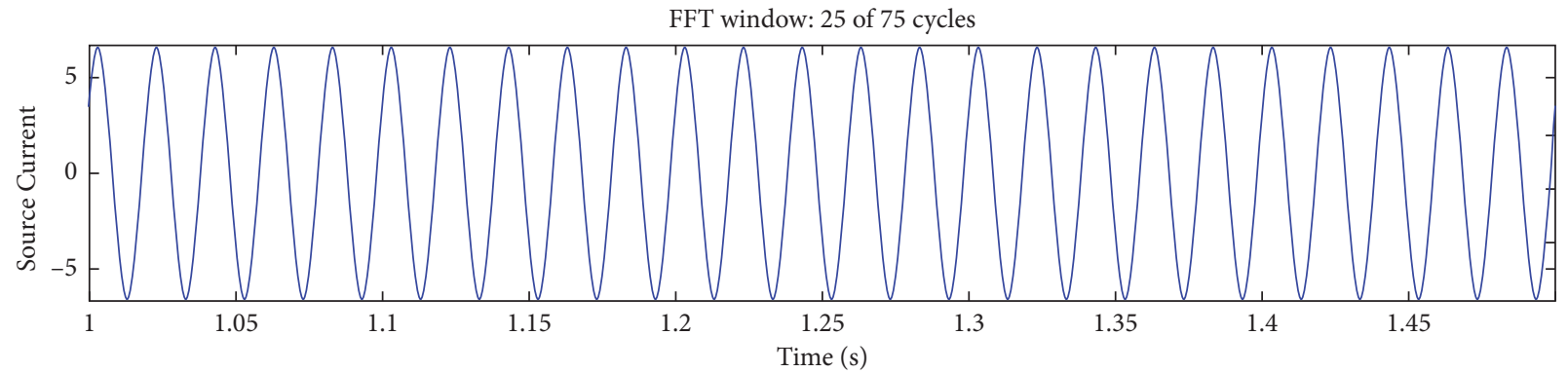

FiguRe 26: Load current IL FFT with HAPF based DQ-Theory.



Figure 27: Load current $I_{L}$ THD with HAPF measured THD of $1.38 \%$ after applying the filter. 
TABLE 2: HAPF control technique result and comparison with past work and standards.

\begin{tabular}{|c|c|c|c|c|}
\hline $\begin{array}{l}\text { Proposed HAPF control } \\
\text { technique }\end{array}$ & THD without HAPF (\%) & THD with HAPF (\%) & $\begin{array}{c}\text { IEEE STD } 519 \text { BS } \\
\text { EN61000-3-2:2019 [29] }\end{array}$ & $\begin{array}{c}\text { From literature, other } \\
\text { works [34] }\end{array}$ \\
\hline PQ-Hysteresis (\%) & 46.58 & 1.51 & $<5 \%$ & \multirow{2}{*}{3.29} \\
\hline DQ-hysteresis & 46.58 & 1.38 & $<5 \%$ & \\
\hline
\end{tabular}



FIgURE 28: System THD with HAPF result attained using proposed PQ and DQ techniques.

\section{Results Comparison between HAPF Based on PQ and DQ Method}

HAPF design and modeling of Single-Phase Instantaneous PQ technique and Single-Phase DQ Reference technique are carried out to mitigate THD of UPS system and connected load. The results are given for both techniques in Table 2, and the proposed models' THD results obtained without the HAPF filter is $46.58 \%$, and after HAPF application, obtained THD $1.51 \%$ and $1.38 \%$ as compared with the past work $3.29 \%$ [34] which meets the international standard requirement of harmonics and should be less than $5 \%$ as per IEEE STD-519-1992 [32]. Also, Table 2 demonstrates that DQ is a more effective method than the PQ method in mitigating the THD of the system.

The results attained with proposed HAPF is designed on the basis of experimental results of UPS system THD by interface using Optical USB and Power Quality Meter for analyzing Total Harmonic Distortion for UPS via DQbased technique. The comparison between both PQ and DQ based techniques are demonstrated in Figure 28. It has been defined that, for PQ and DQ Hysteresis without using the HAPF, the values are similar as of $46.58 \%$, and system has the harmonics and disturbance for both techniques. However, with using the proposed HAPF based on PQ and DQ Hysteresis control technique, the THD has been dropped significantly, and it is noted that system THD achieved less than 1.51\% using HAPF based on PQ technique and system THD achieved less than $1.38 \%$ using HAPF based on DQ technique which is a significant decrease. In comparison to both PQ and DQ, the DQ has achieved the better results than PQ. The hybrid active power filter added with the UPS system to reduce harmonics and give pure sinusoidal waveform that diminished the UPS losses from specific values that are recorded.

\section{Conclusion}

In this paper, authors have proposed novel Single-Phase HAPF for the UPS system and connected nonlinear load, and HAPF is developed on basis of THD experimental results of the UPS system. Other main key aspect of this research work is Hybrid Interface using Optical USB and Power Quality Meter for experimental Total Harmonic Distortion analysis of the UPS system. The UPS efficiency and THD are measured using the real-time designed interface. Mathematical modeling of HAPF is provided using PQ and DQ theory, and the hysteresis controller is used for VSI of HAPF, and the PI controller is also used for maintaining the DC bus voltage ( $V_{\mathrm{dc}}$ capacitor) of the inverter. HAPF modeling is performed in Simulink Matlab. It is concluded from the waveform analysis and results that HAPF based on the PQ hysteresis controller eliminates the THD effectively from 46.58 to $1.51 \%$, where as HAPF based on the DQ hysteresis controller eliminates the THD effectively from 46.58 to $1.38 \%$, also improves power quality of the supply system, decreases power losses, and improves performance. Hence, it has been proved that DQ Technique is more effective than PQ Technique and meets the international IEEE STD-519-1992 for harmonics should be less than $5 \%$. The proposed work also gives a direction for 
enhancing mitigation of harmonics using the advanced modification in the schemes to DQ Hysteresis Technique using neural and fuzz logic.

\section{Data Availability}

No data were used to support the findings of the study.

\section{Conflicts of Interest}

The authors declare that they have no conflicts of interest regarding the publication of this article.

\section{Acknowledgments}

The authors are grateful to all faculty members of Electrical Engineering Department, MUET Jamshoro and Director IICT for providing the necessary infrastructure to carry out the paper work at the institute.

\section{References}

[1] Y. Du, D. D. C. Lu, A. Zobaa, S. H. E. A. Aleem, and M. E. Balci, "Harmonic distortion caused by single-phase grid-connected PV inverter," in Power System Harmonics: Analysis, Effects and Mitigation Solutions for Power Quality Improvement, Intech Open, London, UK, 2018.

[2] N. Hamzah, Z. Zakaria, A. Mohamed, and A. Hussain, "A novel software tool for power quality diagnosis," in 2008 IEEE 8th International Conference on Computer and Information Technology Workshops, pp. 625-630, IEEE, Washington, DC, USA, July 2008.

[3] F. Guihong, Z. Jing, Z. Yisong, Y. Yong, and Z. Bingyi, "Harmonic power detection and measurement device based on harmonic power flow analysis," in 2005 International Conference on Electrical Machines and Systems, vol. 3, pp. 2262-2265, IEEE, Beijing, China, September 2005.

[4] M. Kezunovic and Y. Liao, "A novel software implementation concept for power quality study," IEEE Transactions on Power Delivery, vol. 17, no. 2, 2002.

[5] M. Ferrari, "Evaluation of harmonic detection algorithms for active power filter based on voltage and current detection methods," in 2018 9th IEEE International Symposium on Power Electronics for Distributed Generation Systems (PEDG), pp. 1-8, IEEE, Charlotte, NC, USA, June 2018.

[6] N. Arshad and U. Ali, "An analysis of the effects of residential uninterpretable power supply systems on Pakistan's power sector," Energy for Sustainable Development, vol. 36, pp. 1621, 2017.

[7] J. Huang, C. Li, Z. Cui, L. Zhang, and W. Dai, “An improved grasshopper optimization algorithm for optimizing hybrid active power filters' parameters," IEEE Access, vol. 8, pp. 137004-137018, 2020.

[8] S. K. Khadem, M. Basu, and M. F. Conlon, "Parallel operation of inverters and active power filters in distributed generation system-A review," Renewable and Sustainable Energy Reviews, vol. 15, no. 9, pp. 5155-5168, 2011.

[9] M. Kumar, Z. A. Memon, M. A. Uqaili, and M. H. Baloch, "An overview of uninterruptible power supply system with total harmonic analysis \& mitigation: an experimental investigation for renewable energy applications," International Journal of Computer Science And Network Security, vol. 18, no. 6, pp. 25-36, 2018.
[10] B. Zhao, Q. Song, W. Liu, and Y. Xiao, "Next-generation multi-functional modular intelligent UPS system for smart grid," IEEE Transactions on Industrial Electronics, vol. 60, no. 9, pp. 3602-3618, 2013.

[11] Z. A. Shahani, A. A. Hashmani, and M. M. Shaikh, "Steady state stability analysis and improvement using eigenvalues and PSS: a case study of a thermal power plant in Jamshoro, Pakistan," Engineering, Technology \& Applied Science Research, vol. 10, no. 1, pp. 5301-5306, 2020.

[12] A. Baitha and N. Gupta, "A comparative analysis of passive filters for power quality improvement," in 2015 International Conference on Technological Advancements in Power and Energy (TAP Energy), pp. 327-332, IEEE, Kollam, India, June 2015.

[13] L. Ciufu, C. L. Popescu, and M. O. Popescu, "Experimental mitigation techniques to reduce the Total Harmonic Distortion of low voltage non-linear power sources," in 2017 10th International Symposium on Advanced Topics in Electrical Engineering (ATEE), pp. 138-141, IEEE, Bucharest, Romania, March 2017.

[14] F. Mebrahtu, "Harmonic mitigation techniques in smart distribution network," in Handbook of Research on New Solutions and Technologies in Electrical Distribution Networks, pp. 104-118, IGI Global, Hershey, PA, USA, 2020.

[15] Y. Naderi, S. H. Hosseini, S. Ghassemzadeh et al., "Power quality issues of smart microgrids: applied techniques and decision making analysis," in Decision Making Applications in Modern Power Systems, pp. 89-119, Academic Press, Cambridge, MA, USA, 2020.

[16] Z. AhmedMemon, M. Aslam Uqaili, and M. Ali Unar, "Estimation of compensation current reference using fuzzy logic controller for three-phase hybrid active power filter," International Journal of Computer Applications, vol. 43, no. 11, pp. 16-21, 2012.

[17] Z. A. Memon, M. A. Uqaili, and M. A. Unar, "Design of threephase hybrid active power filter for compensating the harmonic currents of three-phase system," 2016.

[18] M. E. Mahadan, "Simulation of a single-phase active power filter based ANN controller," Doctoral dissertation, Universiti Tun Hussein Onn Malaysia, Parit Raja, Malaysia, 2013.

[19] C. Gong, W. K. Sou, and C. S. Lam, "Second-order sliding mode current controller for LC-coupling hybrid active power filter," IEEE Transactions on Industrial Electronics, vol. 21, 2020.

[20] S. H. Memon, M. Kumar, A. H. Memon, Z. A. Memon, and S. A. Soomro, "Total harmonic distortion (THD) analysis of grid integrated permanent magnet synchronous generator (PMSG) with full scale converter (FSC) based wind farm," IJCSNS, vol. 18, no. 12, p. 232, 2018.

[21] Z. A. Memon, M. A. Uqaili, and M. A. Soomro, "Experimental analysis of harmonic mitigation effects on three phase six pulse converter by using shunt passive filter," Mehran University Research Journal of Engineering and Technology, vol. 30, no. 4, pp. 653-656, 2011.

[22] K. Kamel, Z. Laid, K. Abdallah, and K. Anissa, "Comparative analysis on shunt active power filter based PQ control strategy using HCC, SPWM and SVPWM switching signal generation techniques," in 2018 15th International Multi-Conference on Systems, Signals \& Devices (SSD), pp. 936-940, IEEE, Hammamet, Tunisia, March 2018.

[23] N. Devarashetti, Y. Reddy, and P. V. Kishore, "Design and simulation of hybrid active power filter using the adaptive fuzzy dividing frequency-control method," International 
Journal of Scientific Engineering and Research, vol. 2, pp. 1-9, 2011.

[24] A. K. Mishra, P. K. Ray, R. K. Mallick, A. Mohanty, and S. R. Das, "Adaptive fuzzy controlled hybrid shunt active power filter for power quality enhancement," Neural Computing \& Applications, vol. 33, no. 5, pp. 1435-1452, 2021.

[25] A. Mortezaei, C. Lute, M. G. Simoes, F. P. Marafão, and A. Boglia, "PQ, DQ and CPT control methods for shunt active compensators-a comparative study," in 2014 IEEE Energy Conversion Congress and Exposition (ECCE), pp. 2994-3001, IEEE, Pittsburgh, PA, USA, September 2014.

[26] N. Jain and A. Gupta, "Comparison between two compensation current control methods of shunt active power filter," International Journal of Engineering Research and General Science, vol. 2, no. 5, pp. 603-615, 2014.

[27] A. A. Imam, R. Sreerama Kumar, and Y. A. Al-Turki, "Modeling and simulation of a PI controlled shunt active power filter for power quality enhancement based on P-Q theory," Electronics, vol. 9, no. 4, p. 637, 2020.

[28] G. Tsengenes and G. Adamidis, "Shunt active power filter control using fuzzy logic controllers," in 2011 IEEE International Symposium on Industrial Electronics, pp. 365-371, IEEE, Langkawi, Malaysia, June 2011.

[29] M. A. Omran, I. I. Mohd, A. Z. Ahmad et al., "Utilization of filter harmonic current based on shunt HPF within the acceptable IEEE-519 Standard," in InECCE2019, pp. 849-858, Springer, Singapore, August 2020.

[30] M. A. Omran, I. I. Ibrahim, A. Z. Ahmad et al., "Comparisons of PI and ANN controllers for shunt HPF based on STF-PQ algorithm under distorted grid voltage," International Journal of Power Electronics and Drive Systems, vol. 10, no. 3, p. 1339, 2019.

[31] J. Wu, T. Liu, T. Qiu, and D. Xu, "Current and power quality multi-objective control of virtual synchronous generators under unbalanced grid conditions," Journal of Power Electronics, vol. 65, pp. 1-10, 2020.

[32] Z. Y. Tham, Y. Hoon, and M. A. Mohd Radzi, "Synchronous reference frame with finite impulse response filter for operation of single-phase shunt active power filter," in MATEC Web of Conferences, vol. 335, p. 2004, EDP Sciences, Pilsen, Czech Republic, September 2021.

[33] L. Asiminoaei, F. Blaabjerg, and S. Hansen, "Evaluation of harmonic detection methods for active power filter applications," in Applied Power Electronics Conference and Exposition, 2005. APEC 2005. Twentieth Annual IEEE, vol. 1, pp. 635-641, IEEE, Austin, TX, USA, March 2008.

[34] J. Fei, S. Zhang, and J. Zhou, "Adaptive sliding mode control of single-phase shunt active power filter," Mathematical Problems in Engineering, vol. 2012, Article ID 809187, 2012. 